\title{
PRODUÇÃO CIENTÍFICA EM RELAÇÕES DE TRABALHO E GESTÃO DE PESSOAS (2000/2017)
}

\author{
SCIENTIFIC PRODUCTION IN LABOR RELATIONS AND \\ PEOPLE MANAGEMENT (2000/2017)
}

\section{PRODUCCIÓN CIENTÍFICA EM RELACIONES DE TRABAJO Y GESTIÓN DE PERSONAS (2000/2017)}

\author{
Catia Eli Gemelli \\ Professora no Instituto Federal de Educação, Ciência e \\ Tecnologia do Rio Grande do Sul/Campus Osório \\ Doutoranda em Administração na Universidade Federal \\ do Rio Grande do Sul \\ catia.gemelli@osorio.ifrs.edu.br
}

\author{
Aline Mendonça Fraga \\ Doutoranda em Administração na Universidade Federal \\ do Rio Grande do Sul, área Gestão de Pessoas e \\ Relações de Trabalho \\ alinemf.adm@gmail.com \\ Vanessa Amaral Prestes \\ Doutoranda em Administração na Universidade Federal \\ do Rio Grande do Sul, área Gestão de Pessoas e \\ Relações de Trabalho \\ vanessa.amaral.prestes@gmail.com
}

\author{
Contextus \\ ISSNe 2178-9258 \\ Organização: Comitê Científico Interinstitucional \\ Editor-Chefe: Diego de Queiroz Machado \\ Avaliação: double blind review pelo SEER/OJS \\ Recebido em 12/05/2019 \\ Aceito em 21/06/2019 \\ Versão final em 09/07/2019 \\ http://dx.doi.org/10.19094/contextus.v17i2.41214
}

\section{RESUMO}

As conexões entre Relações de Trabalho (RT) e Gestão de Pessoas (GP) são inevitáveis, visto que ambas envolvem interações em contexto de trabalho. Este estudo objetivou mapear a produção científica das áreas, dos anos 2000 a 2017, dos artigos indexados na base de dados Web of Science (WoS). A partir de análise bibliométrica quantitativa-descritiva, examinou-se o comportamento da literatura nacional e internacional em relação a sua distribuição temporal, por idioma e por periódicos, bem como frequência de autoria e de palavras-chaves. Como principais resultados, evidenciam-se: crescimento expressivo nas publicações; predomínio de publicações e periódicos em inglês e oriundos do Reino Unido e da América do Norte; e prevalência do inglês como língua de origem dos principais autores. Como temáticas destacaram-se: relações com os sindicatos, inovação e estudos focados em países com economia em expansão (no contexto internacional); mercado de trabalho, sustentabilidade, cultura e clima organizacional, diversidade, expatriação (no contexto nacional).

Palavras-chave: relações de trabalho; gestão de pessoas; bibliometria; produção científica; Web of Science.

\begin{abstract}
The connections between Work Relationships and People Management are inevitable, since both involve interactions in the work context. This study aimed to map the scientific production of the areas indexed in the Web of Science (WoS) database from 2000 to 2017. From a quantitative-descriptive bibliometric analysis, it was examined the behavior of the national and international literature in relation to its temporal distribution, by language and periodicals, as well as frequency of authorship and keywords. The main results are: expressive growth in publications; predominance of English-language journals and journals from the United Kingdom and North America; and prevalence of English as the mother language of the main authors. The subjects highlighted were: relations with trade unions, innovation and studies focused on countries with economies in expansion (in the international context); labor market, sustainability, culture and organizational climate, diversity, expatriation (in the national context).
\end{abstract}

Keywords: labor relations; people management; bibliometric; scientific production; Web of Science. 


\section{RESUMEN}

Las conexiones entre Relaciones de Trabajo y Gestión de personas son inevitables, ya que ambas implican interacciones en el contexto de trabajo. Este estudio objetivó mapear la producción científica de las áreas, desde 2000 hasta 2017, de los artículos indexados en la base de datos Web of Science (WoS). A partir del análisis bibliométrica cuantitativa-descriptiva, se examinó el comportamiento de la literatura nacional e internacional en relación con su distribución temporal, por idioma y por periódicos, así como frecuencia de autoría y de palabras clave. Como principales resultados, se evidencian: crecimiento expresivo en las publicaciones; predominio de publicaciones y periódicos en inglés y oriundos del Reino Unido y de América del Norte; y la prevalencia del inglés como lengua de origen de los principales autores(as). Como temáticas se destacaron: relaciones con los sindicatos, innovación y estudios enfocados en países con economía en expansión (en el contexto internacional); mercado de trabajo, sostenibilidad, cultura y clima organizacional, diversidad, expatriación (en el contexto nacional).

Palabras clave: relaciones de trabajo; gestión de personas; bibliometria; producción científica; Web of Science.

\section{INTRODUÇÃO}

A necessidade de que as temáticas pertencentes às áreas de estudos de Relações de Trabalho (RT) e Gestão de Pessoas (GP) sejam trabalhadas de forma vinculada, configurando inclusive uma única área de pesquisa, destaca-se como preocupação para diversos estudiosos (KAUFMAN, 2002; BARBOSA, 2005; DELBRIDGE; HAUPTMEIER; SENGUPTA, 2011; CARVALHO NETO, 2012; CARVALHO NETO; SANT'ANNA, 2013; SARSUR et al., 2017). Apesar do registro, desde o início da década de noventa, de ensaios teóricos que defendem a urgência de pesquisas dessa natureza, Sarsur et al. (2017) concluíram que houve pouco esforço dos pesquisadores em responder a esse apelo, sendo raras ou quase inexistentes pesquisas que integrem RT e GP em uma única área.

Argumenta-se que RT e GP podem ser analisadas de forma integrada, visto que constituem temáticas diretamente relacionadas, quiçá, inseparáveis. Entende-se que ambas envolvem a interação entre pessoas em contexto de trabalho, em trocas remuneradas ou não. As conexões entre RT e GP são inevitáveis e, dessa forma, não há como pensar políticas e práticas trabalhadas nas organizações, olhar comum à GP, sem considerar o impacto ocasionado para os modos de trabalhar e viver em uma perspectiva ampliada, possibilitada pela RT (FERRAZ; OLTRAMARI; PONCHIROLLI, 2011).

Cabe ressaltar que, recentemente, Programas de Pós-Graduação e congressos ligados à Administração em âmbito nacional, têm adaptado suas nomenclaturas para RT e GP, o que indica a visão conjunta como preocupação acadêmica vigente. Como exemplo de programa de pós-graduação, pode-se citar o da Universidade Federal do Rio Grande do Sul, que possui como uma de suas áreas de concentração Gestão de Pessoas e Relações de Trabalho. Dentre os principais eventos nacionais promovidos na área estão o Encontro de Gestão de Pessoas e 
Relações de Trabalho (EnGPR), evento que ocorre no intervalo de dois em dois anos sob promoção da Associação Nacional de Pós-Graduação e Pesquisa em Administração - ANPAD, e possui uma subdivisão de onze temas de interesse, e o Encontro da Anpad - EnANPAD, evento anual, também organizado pela ANPAD e subdividido em onze divisões acadêmicas, sendo uma delas nominada Gestão de Pessoas e Relações de Trabalho.

Levando em conta que a base de conhecimento de qualquer área científica é a literatura publicada, novas contribuições costumam emergir a partir de publicações anteriores. Por esse motivo, uma das características mais importantes da prática científica tem sido observar o crescimento da literatura coletada e indexada em bases de dados bibliográficos especializadas (URBIZAGASTEGUI; RESTREPO-ARANGO, 2017). Estudos que analisam a produção de um campo científico são relevantes por permitirem delinear o conhecimento já produzido e traçar perspectivas que podem ser exploradas no futuro. Além disso, fundamentam a percepção do imprescindível aos/às pesquisadores/as: atenção ao conhecimento já gerado no seu campo de estudo para direcionar a realização de novas pesquisas.

Relativamente à produção científica brasileira, foi identificado apenas um estudo (MACÊDO et al., 2016) sobre GP e RT conjuntamente, no entanto, seu foco foram as publicações de um evento acadêmico. Os autores e autoras analisaram as publicações dos anais do Encontro de Gestão de Pessoas e Relações de Trabalho (ENGPR). Ademais, pode-se citar que estudos sobre a literatura na área de GP (CALDAS; TONELLI; LACOMBE, 2002; TONELLI; CALDAS; LACOMBE; TINOCO, 2003; OLTRAMARI, 2008; BARRETO et al., 2011; DEMO et al., 2011; GALLON; BITENCOURT; CAMILLIS; SCHEFFER, 2013; MASCARENHAS; BARBOSA, 2013; SILVA; ORSI; NAKATA, 2013; DEMO; FOGAÇA; FERNANDES; SÁ, 2015; MENESES et al., 2014; VENÂNCIO; MARTINS; DUTRA; STEINBACH, 2014; ARMOND et al., 2016; DEMO; FOGAÇA; COSTA, 2018) e de RT (CASSUNDÉ; BARBOSA; MENDONÇA, 2016; OLIVEIRA; LIMA; MORAIS, 2016) trouxeram grandes contribuições para o mapeamento e, consequentemente, compreensão dessas áreas.

Diante de tais aspectos, o presente artigo objetiva mapear a produção científica das áreas de Gestão de Pessoas e Relações de Trabalho, dos anos 2000 a 2017, com referência aos seguintes elementos: distribuição temporal; distribuição por idiomas; distribuição por periódicos; frequência de autoria e frequência de palavras-chaves no contexto internacional e nacional. Para tal, realizou-se uma análise bibliométrica com foco nos artigos indexados na base de dados Web of Science $(W o S)$, a partir da aplicação do método quantitativo-descritivo. 
Este artigo está dividido em cinco partes: a esta introdução segue a revisão teórica da pesquisa que faz um apanhado histórico de RT e GP, indicando suas inter-relações e tensões, seguida do método de pesquisa, da análise dos resultados e da discussão final.

\section{REFERENCIAL TEÓRICO}

Relações de Trabalho (RT) e Gestão de Pessoas (GP), são áreas de estudos originárias dos Estados Unidos da América e pertencentes à grande área de Ciências Sociais Aplicadas. O caminho da área de GP, especialmente, passou por mudanças de nomenclatura (LEGGE, 2005), enquanto foi se firmando e apresentando suas próprias associações, disciplinas, congressos e periódicos.

As origens datam do século XIX, devido à necessidade de registro do trabalho, em suma, contabilização das horas de atividade, faltas e atrasos e, a partir disso, definição dos pagamentos e descontos. Por volta da década de 1910, em território norte-americano, mesma época em que Frederick Taylor lançou "Os Princípios da Administração Científica”, as preocupações com a maximização da eficiência eram o incentivo principal no olhar de gestores para os/as trabalhadores/as. Após a Primeira Grande Guerra, as áreas de RT e GP popularizaram-se internacionalmente com as denominações de Industrial Relations e Human Resource Management, respectivamente (CARVALHO NETO; SANT'ANNA, 2013; MARRAS, 2016). As duas áreas, embora dividam a mesma origem contextual, temporária e espacial, suscitam distinções e parecem seguir caminhos diferentes, especialmente em âmbito nacional.

Com a terminologia Industrial Relations, ou Relações de Trabalho, como foi traduzida no Brasil, passou a ser consolidada internacionalmente a partir dos anos de 1980. A abrangência incluía aspectos do trabalho e as mais variadas questões que afetam empregados/as e empregadores/as, bem como práticas de organizações de trabalhadores/as e empregadores/as (CARVALHO NETO; SANT'ANNA, 2013). Para Fisher (1987), a área contempla diversas formas de relacionamento social, por isso seu caráter amplo e extensivo. Ademais, alcança espaço social e político ao abordar temas como a organização do processo de trabalho, a elaboração de políticas organizacionais e as práticas cotidianas dos agentes sociais. Carvalho Neto e Sant'Anna (2013) apontam que o entendimento contempla, evidentemente, questões específicas de GP e, portanto, as áreas devem ser consideradas conjuntamente. 
O entendimento de Human Resources Management - a Gestão de Recursos Humanos, foi importado das escolas norte-americanas. Na década de 1950, mesma época do auge da Escola de Relações Humanas, a denominação conectou-se com a área das ciências humanas. Os norte-americanos, por modismo, nos anos 1960 separavam a gestão de relações industriais da gestão de recursos humanos - o/a gerente de uma cuidava dos aspectos administrativos e o/a outro/a da parte "humana" (MARRAS, 2016; WOOD JR; TONELLI; COOK, 2011). No contexto brasileiro, a nomenclatura vem sendo atualizada por terminologias características do vocabulário do management. Do Departamento Pessoal para a Administração Recursos Humanos surge, posteriormente, a Gestão de Recursos Humanos e, com ideais de estratégia, a Gestão de Pessoas, Gestão de Talentos e Gente e Gestão.

Em relação à produção internacional em GP, esta foi impulsionada a partir dos anos de 1970, como resultado das movimentações mundiais ocorridas com a liberalização econômica, abertura dos mercados internacionais e, principalmente, da consolidação de conglomerados empresariais, exigentes de estratégias voltadas ao recrutamento e manutenção de equipes de trabalho. Ainda que o olhar de GP permita alcançar diferentes esferas do relacionamento humano, quer seja, individual, organizacional, societal ou global, a disciplina acadêmica, historicamente, ancorou-se em torno de uma agenda que privilegiou as necessidades da gestão em contratar, treinar, recompensar, motivar e desenvolver pessoas com talentos considerados importantes para as organizações (WRIGHT; DUNFORD; SNELL, 2001; BOXALL, 2014).

No Brasil, a produção acadêmica voltada à GP até o ano de 1980 era escassa e não representava questões da realidade nacional. Mediada pelas influências da Psicologia e da Sociologia, o escopo da área foi se expandido na década posterior, contudo, embora as pesquisas "tenham aumentado significativamente em volume, guardam um perfil acadêmico de baixa consistência e qualidade" (TONELLI; CALDAS; LACOMBE; TINOCO, 2003, p. 119). Baixa diversidade epistemológica, base eminentemente funcionalista e o papel de coadjuvante e reprodutora de pesquisas internacionais são desafios a serem superados. Tais pontos, destacados pelos/as autores/as, pouco mudaram no período entre 2001 e 2010, mantendo um receituário de GP em contexto brasileiro que, na pesquisa, carece de diversificação metodológica no desenho e delineamento (MENESES et al., 2014). As prescrições são refletidas não só na pesquisa, mas também nas empresas: estudiosos e praticantes de GP são vistos com descrédito (LEGGE, 2005).

Em geral, o campo de RT é associado a um olhar macro (a exemplo de pesquisas sobre relações entre os atores sociais coletivos e análise de perfis do mercado de trabalho), ao passo 
que a área de GP é vista a partir de uma perspectiva micro (a exemplo de estudos acerca da ação individual na organização). Ademais, pesquisas em RT centram sua análise predominantemente na força dos contextos, sobretudo externos à organização. Já em GP trabalha-se com a noção de contexto condicionante, mas não determinante, ou seja, considera-se que aspectos internos podem ser predominantes em relação aos externos (CARVALHO NETO, 2012).

Delbridge, Hauptmeier e Sengupta (2011) reforçam como ponto de tensão entre os estudos a oposição entre o olhar interno das discussões de GP, com foco na perspectiva organizacional, em detrimento do olhar externo, adotado mais comumente em estudos associados a RT, com foco em questões econômicas, institucionais e sociais. Patton (1994), por sua vez, considerava que na medida em que o mote é facilitar e aproximar gestores e equipes de forma produtiva e que impulsione seu desenvolvimento, pode ser considerada como um sinônimo de RT.

Percebe-se que o conflito entre as áreas coloca em xeque o caráter ditado pelas melhores práticas, foco elementar das pesquisas em GP. Tal perspectiva parece privilegiar questões atinentes à gestão de grandes corporações e negligenciar outras vivenciadas pelas diversas configurações organizacionais existentes, como pequenas e médias empresas, organizações horizontais e outras do contexto contemporâneo, a exemplo das startups e das empresas virtuais. A agenda de discussão e pesquisa atual aproxima diretamente suas interfaces, uma vez que falar em RT implica diretamente em falar sobre GP (KAUFMAN, 2010). Mudanças nos padrões de competição em nível macroeconômico mundial culminaram na exigência de novas formas de RT, exigindo por parte do nível estratégico das grandes empresas políticas e práticas de GP mais alinhadas à estratégia organizacional. A abordagem estratégica de GP, ao pensá-la integrada à vantagem competitiva da empresa, contribuiu para abrir a possibilidade de integrála a uma perspectiva que considera fatores econômicos e sociais no nível macro, como é o caso de RT (CARVALHO NETO; SANT’ANNA, 2013).

Essa mudança de foco da Administração de Recursos Humanos para a criação de contribuições estratégicas em GP, é nomeada como Gestão Estratégica de Pessoas (GEP), e destacou-se no campo científico brasileiro a partir do ano de 2005 (ARMOND et al., 2016). A GEP nasceu da integração das atividades de RH com o planejamento estratégico das organizações e da necessidade de que as políticas de GP fossem coerentes com as outras políticas da organização (LACOMBE; TONELLI, 2001). A GEP estuda como as relações de trabalho são gerenciadas de forma a alcançar metas, já que as pessoas e suas interações são fundamentais na consecução dos objetivos organizacionais (LEGGE, 2005). 


\section{METODOLOGIA}

O presente estudo se caracteriza como descritivo, de natureza quantitativa, baseado em indicadores e análises bibliométricas. A bibliometria é uma técnica quantitativa e estatística de medição dos índices de produção e disseminação do conhecimento científico e consiste na aplicação de técnicas matemáticas e estatísticas para descrever aspectos da literatura (ARAÚJO; ALVARENGA, 2011). Os estudos bibliométricos colaboram, sobretudo, no sentido de sistematizar as pesquisas realizadas em determinado campo de saber e endereçar problemas a serem investigados em pesquisa futuras (CHUEKE; AMATUCCI, 2015). Dependendo da finalidade do estudo bibliométrico, os dados podem ser tanto o texto que compõe a publicação, como os elementos presentes em registros sobre publicações extraídos de base de dados bibliográficos, como título, idioma, autores, palavras-chave e periódicos (ZHU; CUNNINGHAM; PORTER; CARLISIE, 1999), como é o caso do presente estudo.

Com relação ao corpus de análise, este é composto pelas publicações dos campos científicos "Gestão de Pessoas" e "Relações de Trabalho" indexadas na base de dados multidisciplinar WoS entre os anos 2000 e 2017. A validade das análises bibliométricas para avaliação de pesquisas reside, em grande parte, na representatividade das bases de dados da atividade científica estudada (MONGEON; PAUL-HAUS, 2016). A escolha da base utilizada neste estudo é justificada pela sua reconhecida qualidade, diante do rigor dos seus critérios de indexação, bem como por sua representatividade nos estudos bibliométricos internacionais. A WoS é uma das bases de dados mais importante no nível das revistas científicas mundiais e foi, durante mais de quarenta anos, a maior base de dados bibliométrica existente (ARCHAMBAULT; CAMPBEL; GINGRAS; LARIVIÉRE, 2009). De acordo com Mongeon e Paul-Hus (2016), uma característica importante desta base de dados é que ela inclui todos os tipos de artigos e indexa todos os autores e autoras, endereços institucionais e referências bibliográficas. Ademais, a sua cobertura interdisciplinar somada ao rigor dos seus critérios de indexação, representa uma força significativa para o estudo de diferentes campos científicos, especialmente quando se trata de um mapeamento como o apresentado neste trabalho.

A coleta de dados foi realizada em maio de 2018 na coleção principal da WoS (Advanced Search), utilizando-se a estratégia de busca por tópico (TS). Os resultados foram exportados da base no formato completo, em grupos de 500, conforme número máximo permitido para exportação pela base, e reunidos em arquivo único. A estratégia de busca baseou-se nos termos: 
"Human Resources", "People Management", "Labor Relations", "Labour Relations", "Work Relationships", “Work Relations", "Personnel Management”, “Work Management”, "Human Relations", "Industrial Relations", "Personnel Administration", "Work Administration", "Human Services". Destaca-se que a pesquisa na base, independentemente do país de origem dos periódicos/artigos buscados, exige a utilização dos termos em inglês. Previamente ao início da escrita do artigo solicitou-se que a escolha dos termos fosse validada por dois especialistas, um professor e pesquisador na área de GP, e uma professora e pesquisadora da área de RT. A validação teve como objetivo certificar que a estratégia alcança as possibilidades de investigação, permitindo contemplar o maior número de documentos publicados.

Ainda na etapa de coleta, as publicações foram refinadas por tipologia documentária, sendo selecionadas somente as que se caracterizaram como artigos. Por fim, foram refinadas por categorias da $W o S$, sendo selecionadas aquelas que se relacionam com as áreas de Administração, Economia, Sociologia e Psicologia. As análises foram executadas com auxílio dos softwares BibExcel (agrupamento de dados, conferência do número de registros no download, conferência de registros duplicados e análises descritivas), WordPad (limpeza de dados), Microsoft Excel (tabelas numéricas, estatísticas e gráficos) e Nvivo (consulta de frequência de palavras).

Iniciou-se a pesquisa pelo levantamento e análise da distribuição temporal por décadas das publicações, desde o surgimento da base de dados, bem como dos primeiros registros de cada termo utilizado na estratégia de pesquisa. Após, os artigos correspondentes ao período 2000-2017 foram analisados a partir da sua distribuição temporal por anos; distribuição por idiomas; distribuição por periódicos; frequência de autoria e frequência de palavras-chaves no contexto internacional e nacional. Foram considerados artigos brasileiros aqueles em que, pelo menos um autor, possui filiação com instituições de ensino ou pesquisa brasileiras.

\section{ANÁLISE E DISCUSSÃO DOS RESULTADOS}

Os resultados encontrados na presente pesquisa iniciam por uma análise temporal das publicações indexadas na $W o S$, anteriormente aos anos 2000, seguida pela apresentação do primeiro artigo indexado de cada um dos termos da estratégia de pesquisa. Posteriormente, explorou-se o mapeamento da produção científica das áreas de Gestão de Pessoas e Relações de Trabalho, dos anos 2000 a 2017. 


\subsection{Análise temporal das publicações indexadas na WoS}

Dada a necessidade de conhecer as origens de uma área de pesquisa, iniciou-se o estudo pelo levantamento da distribuição temporal de publicações sobre Gestão de Pessoas e Relações de Trabalho desde o início da indexação na base de dados. Foram encontrados 9.806 artigos publicados a partir do ano de 1945 - ano que marca o início da indexação da principal coleção da WoS (Science Citation Index Expanded) - até o ano de 2017. Destes, 6521 foram publicados após os anos 2000, com acentuado crescimento nos últimos dois anos, tendo em vista que $14,33 \%$ do total de publicações foram nos anos 2016 e 2017.

A Figura 1 apresenta a distribuição temporal da produção em número de artigos por décadas, desde o ano de 1945 até o ano de 2017. Diante da impossibilidade de apresentar a década atual, optou-se por mostrar o potencial de expansão da área a julgar pela quantidade de artigos já indexados somente em 2016 e 2017.

Figura 1 - Distribuição Temporal por Décadas

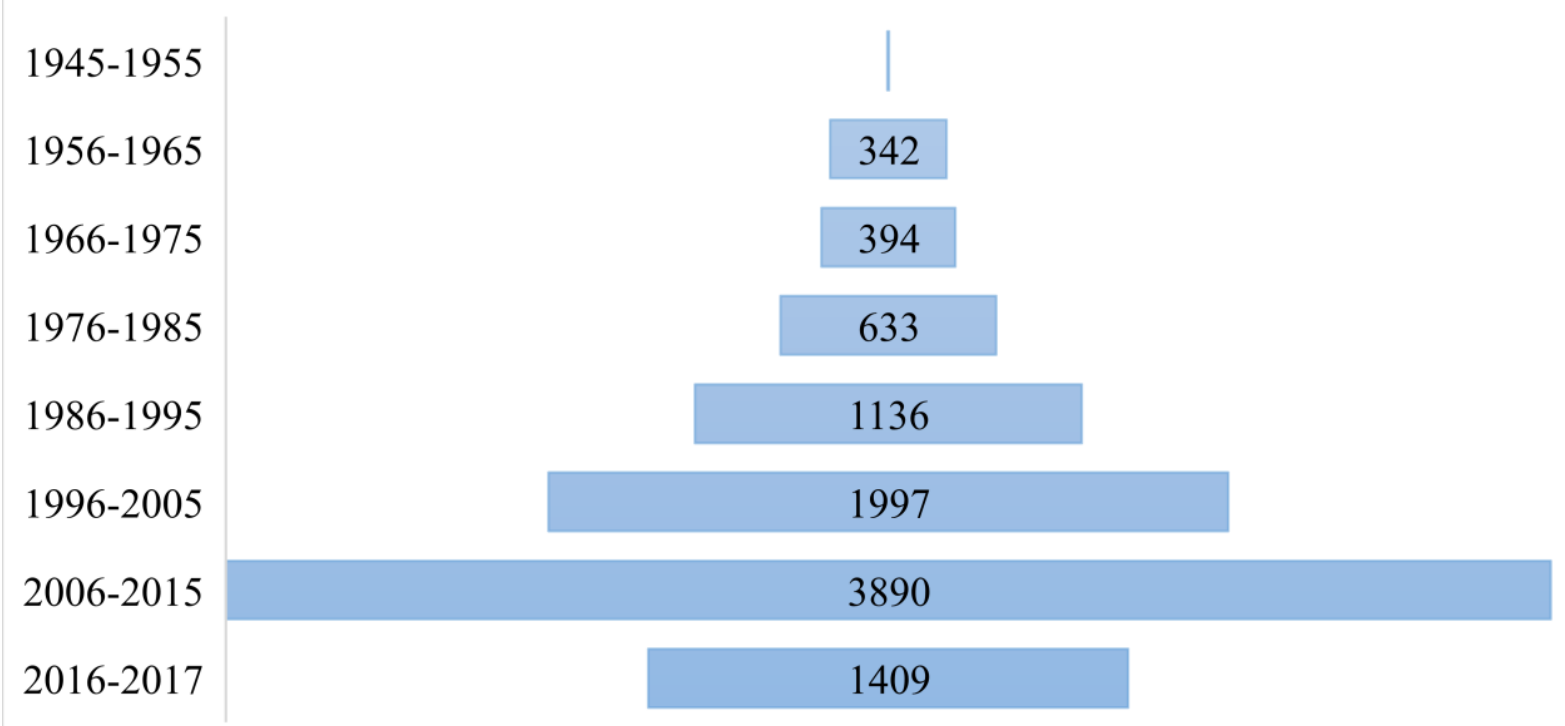

Fonte: elaboração própria, com base nos dados do BibExcel.

Para análise deste cenário de expansão é preciso considerar a influência de diversos fatores, como: surgimento de novos periódicos e eventos especializados na área de Administração, bem como especificamente de GP e RT; aumento da produção científica, bem como da cobrança pela mesma; maior acesso à internet, resultando na maior distribuição das pesquisas científicas; e aumento no número de periódicos indexados na base da WoS. Não obstante, apesar da inegável influência desses fatores, pode-se afirmar que os dados da distribuição temporal dos artigos publicados e indexados, por década, reforçam a 
representatividade do intervalo escolhido para este estudo, visto que $66,5 \%$ do total das publicações foram após os anos 2000.

O primeiro artigo do campo indexado na $W o S$, de autoria da norte-americana Maria Rogers, intitulado Problems of human relations in industry, foi publicado no ano de 1946, na revista Sociometry, da área de Psicologia Social. Neste trabalho, Rogers (1946) argumentou que a ciência social deveria estar preparada para ajudar a indústria em seus problemas humanos, na mesma medida em que as ciências físicas auxiliavam nos problemas da produção. Seu artigo apresentou um breve resumo de pesquisas de ciências sociais, consideradas recentes naquele período, e que foram tomadas como de extrema importância para os negócios e para a indústria.

No que se refere ao contexto brasileiro, o primeiro artigo publicado e indexado na WoS que aborda o Brasil enquanto campo de análise foi publicado no ano de 1966 no International Labour Review, intitulado Problems of human resources in Brazil, de autoria de Robert Nicolaus Dannemann. Já o primeiro artigo em português indexado, intitula-se "Liderança e Relações Humanas no Contexto do Estudo Sociométrico", publicado no periódico Arquivos Brasileiros de Psicologia Aplicada, no ano de 1971, por Edith Ramos.

Objetivando compreender o caminho histórico dos termos utilizados na estratégia de pesquisa, o Quadro 1 apresenta o primeiro artigo registrado na pesquisa de cada termo, por ordem cronológica crescente:

Quadro 1 - Primeiro registro de cada termo

\begin{tabular}{|c|c|c|c|c|}
\hline Termos & Ano & Título & Autoria & Journal \\
\hline $\begin{array}{c}\text { Human } \\
\text { Relations }\end{array}$ & 1946 & $\begin{array}{l}\text { Problems of human } \\
\text { relations in industry }\end{array}$ & $\begin{array}{l}\text { Maria Rogers } \\
\text { (EUA) }\end{array}$ & Sociometry \\
\hline $\begin{array}{c}\text { Personnel } \\
\text { Administration }\end{array}$ & 1946 & $\begin{array}{l}\text { New ways in personnel } \\
\text { administration }\end{array}$ & $\begin{array}{l}\text { Alexander F. } \\
\text { Magoun } \\
\text { (EUA) }\end{array}$ & $\begin{array}{l}\text { American } \\
\text { Journal of } \\
\text { Nursing }\end{array}$ \\
\hline $\begin{array}{l}\text { Industrial } \\
\text { Relations }\end{array}$ & 1947 & $\begin{array}{l}\text { The research programme } \\
\text { of the industrial relations } \\
\text { section, Princeton- } \\
\text { university }\end{array}$ & $\begin{array}{l}\text { Holly Baker } \\
\text { (EUA) }\end{array}$ & $\begin{array}{c}\text { Journal of } \\
\text { Documentation }\end{array}$ \\
\hline $\begin{array}{c}\text { Human } \\
\text { Resources }\end{array}$ & 1947 & $\begin{array}{l}\text { Scientific development of } \\
\text { the use of human } \\
\text { resources: progress in the } \\
\text { Army Air Forces. }\end{array}$ & $\begin{array}{c}\text { Joseph C. } \\
\text { Flanagan } \\
\text { (EUA) }\end{array}$ & Science \\
\hline $\begin{array}{l}\text { Labor } \\
\text { Relations/ } \\
\text { Labour } \\
\text { Relations }\end{array}$ & 1952 & $\begin{array}{c}\text { Increasing Labor } \\
\text { Efficiency through Worker } \\
\text { Training and Improved } \\
\text { Labor Relations }\end{array}$ & $\begin{array}{c}\text { Lewis } \\
\text { Vaughan (CA) }\end{array}$ & $\begin{array}{l}\text { Journal of } \\
\text { Farm } \\
\text { Economics }\end{array}$ \\
\hline
\end{tabular}

(CONTINUA) 
(CONTINUAÇÃO)

\begin{tabular}{|c|c|c|c|c|}
\hline $\begin{array}{c}\text { Personnel } \\
\text { Management }\end{array}$ & 1956 & $\begin{array}{c}\text { Observations on } \\
\text { Personnel-Management in } \\
\text { Latin-America }\end{array}$ & $\begin{array}{c}\text { Tejera-Paris, E } \\
\text { (VE) }\end{array}$ & $\begin{array}{l}\text { Public } \\
\text { Personnel } \\
\text { Review } \\
\end{array}$ \\
\hline $\begin{array}{c}\text { People } \\
\text { Management }\end{array}$ & 1969 & $\begin{array}{c}\text { Utilization of people - } \\
\text { management must meet } \\
\text { challenge }\end{array}$ & $\begin{array}{l}\text { M. H. Mescon } \\
\text { (EUA) }\end{array}$ & $\begin{array}{l}\text { Atlanta } \\
\text { Economic } \\
\text { Review } \\
\end{array}$ \\
\hline $\begin{array}{l}\text { Human } \\
\text { Services }\end{array}$ & 1969 & $\begin{array}{c}\text { Policy Paper - New Look } \\
\text { at Public Planning for } \\
\text { Human Services }\end{array}$ & $\begin{array}{l}\text { Newman, E. } \\
\text { Demone, H. } \\
\text { W. (EUA) }\end{array}$ & $\begin{array}{l}\text { Journal of } \\
\text { Health and } \\
\text { Social } \\
\text { Behavior }\end{array}$ \\
\hline $\begin{array}{c}\text { Work } \\
\text { Administration }\end{array}$ & 1971 & $\begin{array}{l}\text { Developing Specialized } \\
\text { Programs in Social Work } \\
\text { Administration in master's } \\
\text { degree Program - Field } \\
\text { Practice Component }\end{array}$ & $\begin{array}{c}\text { Bernard } \\
\text { Neugeboren } \\
\text { (EUA) }\end{array}$ & $\begin{array}{c}\text { Journal of } \\
\text { Education for } \\
\text { Social Work }\end{array}$ \\
\hline $\begin{array}{c}\text { Work } \\
\text { Relationships/ } \\
\text { Work Relations }\end{array}$ & 1972 & $\begin{array}{l}\text { Toward Building New } \\
\text { Work Relationships - } \\
\text { Action Design for a } \\
\text { Critical Intervention }\end{array}$ & $\begin{array}{l}\text { Golembiewski } \\
\text { R.T. } \\
\text { Blumberg, A } \\
\text { Carrigan, S.B. } \\
\text { Et Al. (EUA) }\end{array}$ & $\begin{array}{l}\text { Journal of } \\
\text { Applied } \\
\text { Behavioral } \\
\text { Science }\end{array}$ \\
\hline $\begin{array}{c}\text { Work } \\
\text { Management }\end{array}$ & 1974 & $\begin{array}{l}\text { From Work Measurement } \\
\text { to Work Management - } \\
\text { From Wage Incentives to } \\
\text { Work Itself }\end{array}$ & $\begin{array}{c}\text { Bittel, L. R } \\
\text { (EUA). }\end{array}$ & $\begin{array}{l}\text { Mechanical } \\
\text { Engineering }\end{array}$ \\
\hline
\end{tabular}

Fonte: elaboração própria a partir da investigação na $W o S$

Analisando os títulos das primeiras publicações sobre RT e GP, aponta-se a hegemonia norte-americana e destaca-se um artigo, proveniente da Venezuela, acerca do contexto latinoamericano. Ademais, reafirma-se a orientação dos estudos com o objetivo de aprimorar as relações industriais (WOOD JR; TONELLI; COOK, 2011), buscando atingir resultados máximos dos trabalhadores, regidos por ordens científicas criadas para garantir a dedicação total ao trabalho em troca de incentivos monetários (MARRAS, 2016). A base de controle dos lucros era formada por um conjunto de regras que envolviam o direcionamento, o desenvolvimento e o controle de trabalhadores, métodos e materiais.

Corroborando os apontamentos desses estudos, percebe-se que a área de GP prioriza aspectos internos das organizações, em detrimento do contexto externo, de nível macro (CARVALHO NETO, 2012). A área, historicamente, centra-se na tentativa de equilibrar os objetivos das organizações com as expectativas de trabalhadores/as, selecionando, treinando e mantendo pessoas comprometidas e motivadas. Desde o surgimento da Escola de Relações Humanas, nos anos 1920, passando pelo surgimento de novas nomenclaturas e direcionamentos 
estratégicos, o foco parece permanecer o mesmo (WRIGHT; DUNFORD; SNELL, 2001; BOXALL, 2014).

Após essa breve análise da distribuição temporal e primeiros registros de RT e GP, a seguir apresenta-se o cenário a partir dos anos 2000 a 2017.

\subsection{Apresentação do cenário dos anos 2000 a 2017}

Os 6521 artigos publicados e indexados na WoS entre os anos 2000 e 2017 foram coletados e passaram pela conferência de dados duplicados no BibExcel, não sendo identificada nenhuma duplicação. Desta forma, o corpus de análise do estudo permaneceu sendo de 6521 documentos. Iniciou-se a análise pela sistematização do número de publicações distribuídas por ano para ilustrar o seu crescimento. De acordo com Urbizagastegui e Restrepo-Arango (2017), o número de artigos científicos publicados a cada ano pode ser considerado uma indicação aproximada da atividade exibida em qualquer área de pesquisa geral ou especializada. A Figura 2 apresenta a distribuição do número de artigos por ano:

Figura 2 - Distribuição Temporal Anual - Período 2000-2017

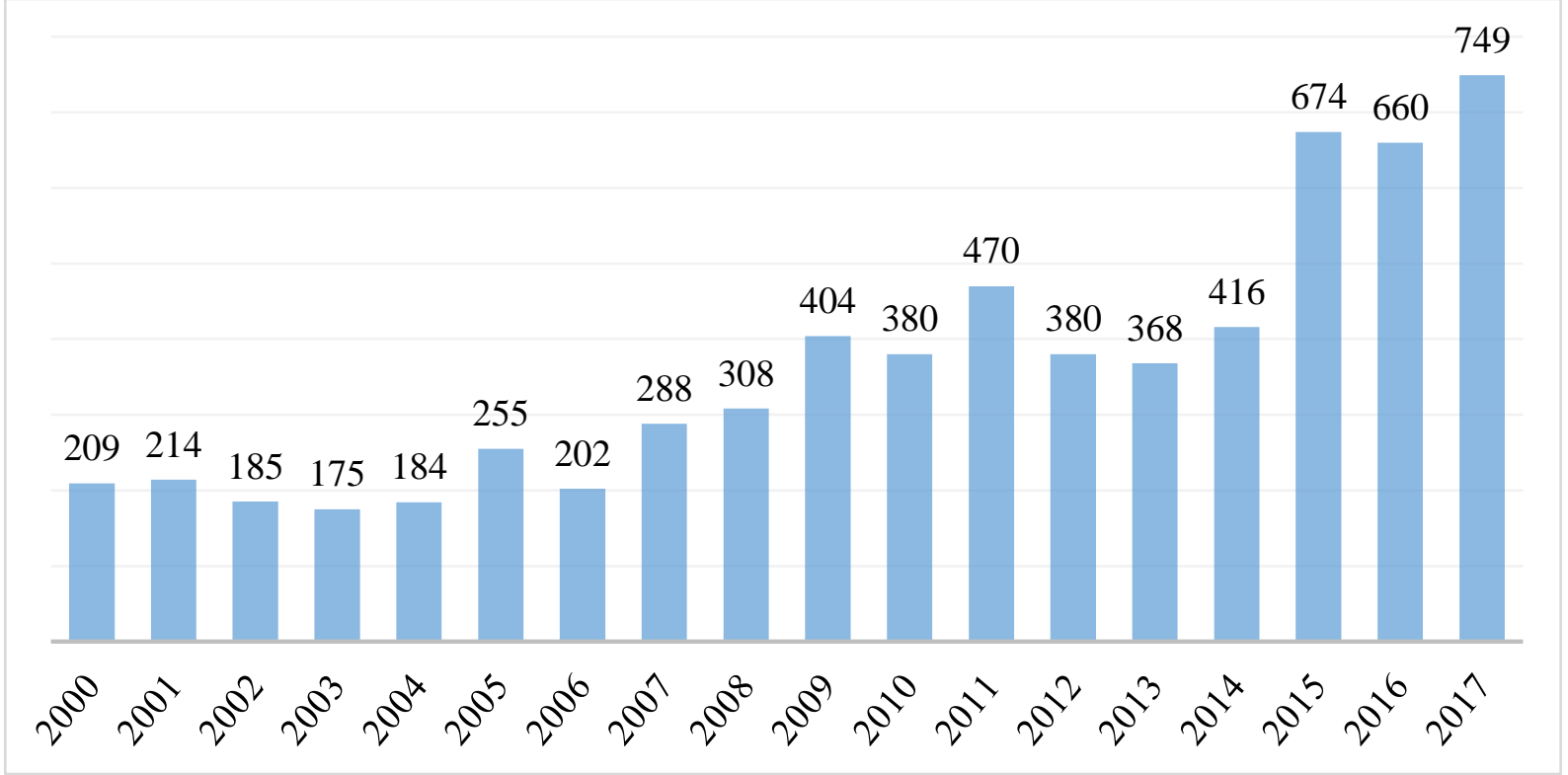

Fonte: elaboração própria com base nos dados do BibExcel.

Como se pode observar no gráfico da distribuição temporal por ano, é claro o crescimento dos estudos das áreas de RT e GP nos últimos doze anos. Ademais, a expansão torna-se ainda mais expressiva a partir do ano de 2015, período em que 2083 artigos foram indexados em apenas três anos. $\mathrm{O}$ ano de 2017 destaca-se como o mais representativo em termos 
de número de artigos publicados, tendo sido 749 , o que equivale à $7,6 \%$ de toda a produção das áreas em setenta e dois anos.

Novamente, é preciso considerar a influência de diversos fatores no crescimento observado no período, a exemplo do surgimento de novas revistas especializadas na área e do aumento no número de periódicos indexados na base da WoS. Entretanto, apesar da evidente influência desses fatores, pode-se afirmar que o interesse pela realização e publicação de estudos em RT e GP vem se expandindo, principalmente nos últimos três anos. Esses dados demonstram a emergência da área no cenário de pesquisas nacionais e internacionais.

Para identificar quais os principais idiomas utilizados na escrita dos artigos, os 6521 foram analisados e distribuídos conforme apresenta a Tabela 2:

Tabela 1 - Distribuição por idioma

\begin{tabular}{c|c|c|c}
\hline Inglês & 5906 & Croata & 9 \\
\hline Espanhol & 173 & Húngaro & 7 \\
\hline Francês & 131 & Polonês & 4 \\
\hline Português & 98 & Ucraniano & 4 \\
\hline Russo & 83 & Holandês & 3 \\
\hline Alemão & 52 & Italiano & 3 \\
\hline Tcheco & 12 & Catalão & 2 \\
\hline Lituano & 10 & Norueguês & 2 \\
\hline Eslovaco & 10 & Japonês & 1 \\
\hline Turco & 10 & Romeno & 1 \\
\hline
\end{tabular}

Fonte: elaboração própria com base nos dados do BibExcel.

Os dados da distribuição dos artigos por idioma de publicação corroboram com os resultados de outras bibliometrias (TONELLI, 2003; MENEGHINI, 2012; PASSOS; VIDA, 2014; MONGEON; PAUL-HAUS, 2016) que evidenciaram a posição dominante do inglês nas ciências. Mongeon e Paul-Haus (2016) identificaram que este idioma se destaca como superrepresentado nos quatro grandes campos da WoS (Natural Science and Engineering, Biomedical Research, Social Sciences, Arts and Humanities).

Sublinha-se que as regras para submissões em periódicos indexados nesta base requerem, em geral, textos na língua inglesa, com a possibilidade de versão na língua do país de origem da publicação. Assim, na intenção de adequarem seus textos para as normas dos periódicos de destaque, autores de diferentes países têm adotado a escrita em inglês, idioma cada vez mais predominante na área da Administração. $O$ fato de o inglês ser considerado a língua oficial da ciência faz com que a publicação neste idioma tenha uma audiência potencial muito maior do que a publicação em outras línguas, causando a percepção comum de que aumenta o impacto das pesquisas (PASSOS; VIDA, 2014). Diante disto, para que a 
internacionalização e o aumento do impacto da produção científica ocorram, a publicação em inglês passou a ser priorizada por diversos periódicos, em diferentes países (Meneghini, 2012).

No entanto, diversos/as autores/as (TONELLI, 2003; BASU, 2010; MENEGHINI, 2012; PASSOS; VIDA, 2014) destacam que essa tendência não é desejável, uma vez que a produção científica em língua nativa pode ser mais adequada para a comunicação de pesquisas de interesse específico para determinado país. Além disso, o número de artigos de países que não tenham o inglês como língua nativa, indexados nessas bases, tem influência decisiva sobre o impacto nas citações da sua produção científica. Isso justificaria a ocorrência comum de periódicos tradicionais brasileiros que publicam trabalhos tanto em inglês, como em português.

Ressalta-se que inúmeras revistas latino-americanas ainda não estão indexadas na $W o S$, o que, por consequência, também pode interferir na quantidade reduzida de publicações em línguas latinas e dificuldades de divulgação local do conhecimento produzido, já que pode tornar-se inacessível. No Brasil, algumas revistas com alto fator de impacto acompanham o movimento de tendência mundial, no sentido de passarem a exigir somente submissões de textos na língua inglesa, ou submissão em duas versões, sendo uma em português e outra em inglês.

Para identificar quais periódicos são mais representativos em termos de número de estudos publicados sobre as áreas de RT e GP, os artigos foram analisados a partir da distribuição por periódicos. A Tabela 3 apresenta a relação dos 10 mais producentes, por ordem decrescente:

Tabela 2 - Relação dos 10 periódicos mais producentes

\begin{tabular}{c|c|c}
\hline Periódico & País & Número de publicações \\
\hline International Journal of Human Resource & Reino Unido & 324 \\
\hline Human Resources for Health & Reino Unido & 214 \\
\hline Journal of Industrial Relations & Estados Unidos & 164 \\
\hline European Journal of Industrial Relations & Estados Unidos & 150 \\
\hline Economic and Industrial Democracy & Estados Unidos & 140 \\
\hline British Journal of Industrial Relations & Reino Unido & 131 \\
\hline Revue Industrielles-Industrial Relations & Canadá & 104 \\
\hline Public Personnel Management & Estados Unidos & 88 \\
\hline Personnel Review & Reino Unido & 82 \\
\hline Administration in Social Work & Estados Unidos & 78
\end{tabular}

Fonte: elaboração própria com base nos dados do BibExcel.

Observa-se, a partir desta relação, a predominância de periódicos do Reino Unido e da América do Norte como mais representativos, em termos de número de artigos publicados sobre as áreas pesquisadas. Novamente, o inglês destaca-se como principal idioma, visto que, com 
exceção do canadense Revue Industrielles-Industrial Relations (periódico bilíngue) os demais periódicos listados são publicados tão somente neste idioma. Ademais, é possível constatar que se trata de revistas de alto fator de impacto e, em sua maioria, especializadas em estudos de RT e/ou GP, ou seja, possuem como escopo publicações exclusivas dessas temáticas.

O primeiro periódico fora do eixo de produção europeu, norte-americano e australiano a aparecer no ranking de produção intitula-se Asia Pacific Journal of Human Resources e ocupa a $21^{\text {a }}$ posição. A Revista Del Clad Reforma y Democracia, publicada pelo Centro Latinoamericano de Administración para el Desarrollo, é a primeira latino-americana e ocupa o $43^{\circ}$ lugar. As primeiras revistas brasileiras aparecem logo após, ambas na $47^{\mathrm{a}}$ posição - a Revista Brasileira de Ciências Sociais e a Revista de Administração de Empresas (RAE). Apesar da posição das revistas brasileiras ainda não ser de destaque, estudos como os realizados por Packer (2011) e Rodrigues, Quartiero e Neuberf (2015) apontam que o Brasil teve seu número de revistas indexadas expandido na $W o S$ no decorrer dos últimos anos.

Além dos periódicos mais representativos, foram identificados/as quais autores/as tiveram o maior número de artigos publicados e indexados na base de dados neste período, a partir da análise de frequência de autoria. A Tabela 4 apresenta o ranking dos/as 10 autores/as mais producentes:

Tabela 3 - Ranking de autores/as mais producentes

\begin{tabular}{c|c|c} 
Autor & $\mathbf{N}^{\mathbf{0}}$ Publicações & País de Origem \\
\hline Miguel Martinez Lucio & 21 & Reino Unido \\
\hline Geoffrey Wood & 18 & Reino Unido \\
\hline Adrian Wilkinson & 18 & Austrália \\
\hline Bruce E. Kaufman & 17 & Estados Unidos \\
\hline Paul Marginson & 17 & Reino Unido \\
\hline Malcon Warner & 16 & Reino Unido \\
\hline Valeria Pulignano & 16 & Bélgica \\
\hline Nicolas Bacon & 15 & Reino Unido \\
\hline Paul Edwards & 14 & Reino Unido \\
\hline John Godard & 13 & Canadá
\end{tabular}

Fonte: elaboração própria com base nos dados do BibExcel.

A partir do ranking de autoria novamente o Reino Unido e a América do Norte aparecem como principais regiões de origem dos/as autores/as mais producentes. Dos/as dez autores/as, apenas um/a é de país cujo idioma oficial não é o inglês. Nenhum/a autor/a da América Latina aparece no ranking dos/as 30 autores/as de maior produtividade em termos de artigos publicados e indexados na $W o S$. Salienta-se que os/a 10 autores/as mais producentes são docentes em Business Schools ou Department of Management de universidades conceituadas 
em seus países de origem, evidenciando a forte relação entre a produção científica e a atuação docente.

Com vistas a identificar quais os principais temas abordados nos estudos, foram extraídas as palavras-chaves de todos os artigos e exportadas para o NVivo, para a conferência de frequência de termos. A Tabela 5 apresenta as 20 palavras-chaves mais evidenciadas com o seu número de citações em ordem decrescente.

Tabela 4 - Relação das 20 palavras-chaves mais citadas

\begin{tabular}{c|c}
\hline $\mathbf{N}^{\mathbf{0}}$ de citações & Palavra-chave \\
\hline 431 & Human Resource Management \\
\hline 383 & Industrial Relations \\
\hline 353 & Human Resources \\
\hline 241 & Trade Unions \\
\hline 194 & China \\
\hline 130 & Collective Bargaining \\
\hline 122 & Innovation \\
\hline 90 & Human Services \\
\hline 88 & Management \\
\hline 83 & Job Satisfaction \\
\hline 82 & Human Capital \\
\hline 75 & Leadership \\
\hline 70 & Performance \\
\hline 57 & Globalization \\
\hline 56 & Germany \\
\hline 55 & Employment \\
\hline 53 & Gender \\
\hline 52 & Personnel Management \\
\hline 52 & Australia \\
\hline 51 &
\end{tabular}

Fonte: elaboração própria com base nos dados do BibExcel.

Analisando esses dados, se observa que as palavras com maior destaque, utilizadas na estratégia de pesquisa, são aquelas diretamente relacionadas à área. Após, o termo sindicatos (Trade Unions) emerge, o que pode revelar as tensões ocorridas pelos distintos interesses de empregadores/as e trabalhadores/as. É interessante que se destaquem nomes de países, como China e Austrália. China e Índia (que aparece mais adiante, na $29^{\circ}$ posição), são economias em expansão para onde as grandes corporações, principalmente norte-americanas, direcionaram sua produção e outros serviços terceirizados, constatou Legge (2005). Com a implantação dessas grandes corporações nestes países, amplia-se o interesse por pesquisas sobre a adaptação da GP em relação à cultura local. A expansão de organizações em nível global potencializa pesquisas acerca das relações de emprego em diferentes contextos, alertando sobre o papel da 
GP com relação a políticas e práticas de expatriação (GALLON; FRAGA; ANTUNES, 2019), os desafios legais de acordos coletivos e a responsabilidade social organizacional (HELFEN; SCHÜßLER; SYDOW, 2018).

O termo gênero, $18^{\circ}$ palavra mais citada, reflete análises em ascensão para RT e GP, principalmente em razão da divisão sexual do trabalho e demais desigualdades encontradas no mercado de trabalho entre homens e mulheres, além de outros debates contemporâneos como a discussão de sexualidade, identidade de gênero, masculinidades e feminilidades. Outras palavras que não figuram na lista apresentada, mas que se destacam entre as 40 primeiras, são: cultura organizacional $\left(24^{\circ}\right)$, responsabilidade social $\left(25^{\circ}\right)$, mudança organizacional $\left(33^{\circ}\right)$, gestão de RH estratégica $\left(38^{\circ}\right)$ e cultural $\left(39^{\circ}\right)$, indicando outras tendências de pesquisa. Importa ressaltar que todas essas palavras são inter-relacionadas e podem fomentar debates do contexto externo às organizações quando aproximadas de gênero.

Por fim, visando identificar quais os temas emergentes no contexto brasileiro, foram extraídas as palavras-chaves de todos os artigos de origem brasileira publicados e indexados na WoS. Conforme ilustra a Figura 3, as 15 palavras-chaves mais citadas nos artigos brasileiros publicados e indexados na $W o S$ no período entre 2000 e 2017, em ordem de frequência, foram: recursos humanos, gestão de pessoas, mercado de trabalho, sustentabilidade, gestão de pessoal, cultura organizacional, clima organizacional, diversidade, expatriação, gestão do conhecimento, gestão estratégica de pessoas, relações trabalhistas, terceirização, turnover e inovação.

Figura 3 - Palavras-chaves mais citadas no contexto brasileiro

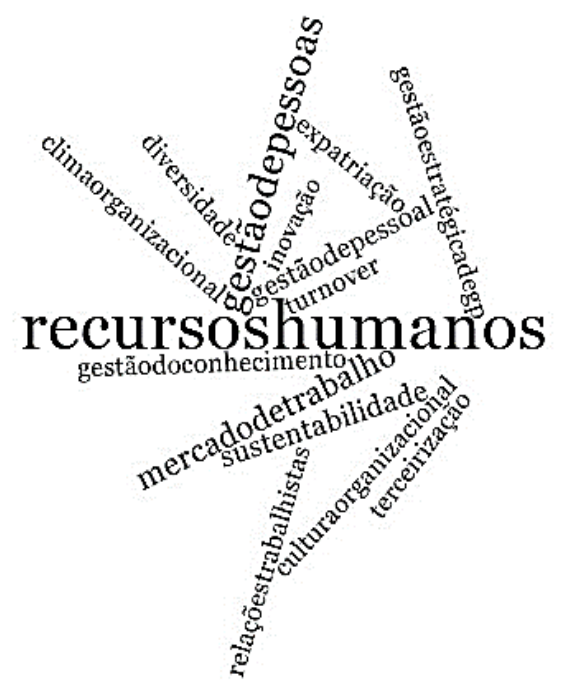

Fonte: elaboração própria com base nos dados do NVivo. 
Percebe-se que, no contexto brasileiro, diversas nomenclaturas são utilizadas para a área de estudos de GP, como já indica a literatura, sendo: recursos humanos, gestão de pessoas, gestão de pessoal e gestão estratégica de pessoas. A terminologia recursos humanos ainda permanece como predominante, apesar dos estudos bibliométricos anteriores, como os de Venâncio, Martins, Dutra e Steinbach (2014) e Armond, et al. (2016) apontarem o crescimento no número de publicações que substituem recursos humanos por gestão de pessoas ou gestão estratégica de pessoas. Carvalho Neto e Sant'Anna (2013), Armond, et al. (2016), Boon, Eckardt, Lepak e Boselie (2017), Paauwe e Boon (2018) e Tonelli e Wilner (2018) destacaram o crescimento da preocupação com a gestão estratégica de GP nacional e internacionalmente, tanto nas organizações, como enquanto tema de pesquisa na área acadêmica. Para os autores, a maior atenção dada para a temática amplia o escopo de análise da área, fato que a aproxima ainda mais dos estudos de RT. O aumento dos indicadores de produção científica sobre a temática entre 2006 e 2015, período analisado por Armond et al. (2016), apontou para uma fase de desenvolvimento da temática de gestão estratégica de pessoas na pesquisa nacional. Esse resultado é corroborado pelos dados do presente estudo, que evidenciam a preocupação com a integração das atividades de GP com o planejamento estratégico das organizações.

Outro tema emergente diz respeito aos estudos que abordam a área de GP relacionada com as temáticas de sustentabilidade e responsabilidade social empresarial, interlocução essa destacada por Freitas, Souza, Teixeira e Jabbour (2013), Napoleão et al. (2014), e Parente e Fisher (2014). Os autores enfatizam a ampliação, tanto nacional como internacional de estudos que envolvam as áreas. Tais estudos possuem como temas mais frequentes a responsabilidade social com o público interno e a gestão estratégica de pessoas. Tais achados reforçam a necessidade do diálogo entre as áreas e de uma visão conjunta para se pensar questões inerentes ao dia a dia dos indivíduos dentro e fora das organizações.

A discussão acerca da terceirização, também indicada como crescente na literatura nacional, pode assumir dois vieses: de reforço ao mainstream funcionalista e gerencialista da área de Administração ou crítico, abordando reflexões sobre a precarização do trabalho (CASSUNDÉ; BARBOSA; MENDONÇA, 2016). A preocupação com os impactos da Reforma Trabalhista e Lei da Terceirização na saúde do trabalhador é um dos temas de estudos recentes como de Torres, Ferreira e Ferreira (2016), Costa, Costa e Cintra (2018) e Belchior (2018). A importância atual deste debate também se evidencia nas chamadas de dossiês de revistas, a exemplo da Revista Jurídica Trabalho e Desenvolvimento Humano e na sua escolha 
como temática central de eventos no ano corrente, como o VI Encontro Nacional da Associação Brasileira de Estudos do Trabalho (ABET).

\section{CONSIDERAÇÕES FINAIS}

Entende-se que as conexões entre RT e GP são inevitáveis, visto que ambas as áreas dialogam sobre a interação de pessoas em contexto de trabalho. Analisá-las de forma integrada possibilita, portanto, o enriquecimento das discussões e o mapeamento da produção de um campo científico coeso. Ademais, considera-se que os estudos bibliométricos, como o realizado neste trabalho, são relevantes por permitirem delinear conhecimento já produzido e traçar perspectivas que podem ser exploradas no futuro.

O presente artigo teve como objetivo mapear a produção científica das áreas de Gestão de Pessoas e Relações de Trabalho, dos anos 2000 a 2017, com referência aos seguintes elementos: distribuição temporal; distribuição por idiomas; distribuição por periódicos; frequência de autoria e frequência de palavras-chaves no contexto internacional e nacional. Para tal, realizou-se a análise bibliométrica de 6521 artigos indexados na base de dados Web of Science $(W o S)$, a partir da aplicação do método quantitativo-descritivo.

No que tange às análises dos resultados, que certamente não esgotam as possibilidades de reflexão, destaca-se o crescimento expressivo nas publicações a partir do ano 2000, sendo que $66,5 \%$ do total dos artigos foram publicados no período de 2000 a 2017. Acentua-se tal resultado nos últimos dois anos, tendo em vista que $14,33 \%$ do total de publicações foram nos anos 2016 e 2017. Como indicado em revisões de literatura e estudos bibliométricos anteriores, observa-se que o termo "recursos humanos" vem sendo substituído por gestão de pessoas e gestão estratégica de pessoas, no entanto, ainda permanece como predominante.

Verificou-se o predomínio do inglês como língua de origem dos/as principais autores/as e, por consequência, de publicações e periódicos em inglês. Destaca-se que 90,6\% dos artigos indexados na WoS, durante o período de análise, foram escritos no idioma e publicados em periódicos oriundos do Reino Unido e da América do Norte - países mais representativos em termos de número de artigos publicados. Esses periódicos são de alto fator de impacto e, em sua maioria, especializados em estudos de RT e/ou GP. O Reino Unido e a América do Norte destacam-se como principais regiões de origem dos/as autores/as mais producentes, a partir de 
dados do ranking de autoria. Além disso, tais resultados reforçam a relação entre a produtividade acadêmica e o exercício docente.

Relativamente às temáticas em evidência na literatura internacional, sobressaem-se as relações com os sindicatos, a inovação, a satisfação no trabalho, os estudos focados em países populosos e com economia em expansão como China e Índia, a liderança, o capital humano e os estudos de gênero. Em âmbito nacional, há maior atenção direcionada para o mercado de trabalho, sustentabilidade, cultura e clima organizacional, diversidade, expatriação, gestão do conhecimento, gestão estratégica de pessoas, relações trabalhistas, terceirização, turnover e inovação. Percebe-se, assim, a pulverização de temas emergentes, resultado que pode indicar a amplitude e a expressividade das áreas.

Enfatiza-se duas importantes convergências entre as principais agendas de pesquisa da área de GP e RT, nos âmbitos nacional e internacional: os estudos sobre inovação em GP e RT e a aproximação das discussões sobre gênero (internacional) e diversidade (nacional). Gênero coloca em debate a própria diversidade de gêneros, para além de homens e mulheres, masculino ou feminino, bem como a diversidade sexual. A diversidade é uma temática em destaque e crescente nas organizações brasileiras, sobretudo a partir dos anos 2000, alinhada com as mudanças demográficas ocorridas nos país, o envelhecimento da população, as mudanças de legislação relativas à inclusão de pessoas com deficiência (PCDs) e as políticas afirmativas de cotas étnico-racias e sociais. O conceito de diversidade envolve a pluralidade da vida social e organizacional e a busca por equidade e inclusão da diferença. Tais aspectos são considerados, outrossim, como impulsionadores da inovação nos espaços organizacionais.

No que concerne à temática da terceirização, o crescimento dos estudos na literatura nacional comparativamente à internacional, na qual o tema não figura como destaque, pode ser um reflexo da publicação da Lei $\mathrm{N}^{\circ} 13.429$, de 31 de março de 2017, que alterou os dispositivos da Lei no 6.019, de 3 de janeiro de 1974, que dispõe sobre as relações de trabalho na empresa de prestação de serviços a terceiros. A discussão sobre essa alteração iniciou nos diversos contextos, incluindo o acadêmico, antes da sua promulgação, ainda na etapa de elaboração. Após sancionada, a lei suscita pesquisas teórico-empíricas no que se refere aos resultados e consequências da sua implantação, o que indica que o tema terceirização apresenta-se como tendência de pesquisa na área para os próximos anos.

Pode-se considerar que uma das limitações deste estudo reside na lacuna de artigos que eventualmente não citem os termos adotados pela estratégia de pesquisa e que podem também 
ter como escopo temas que se inter-relacionam com as áreas de RT e GP. Outrossim, como observado nos resultados e reforçado por diversos estudos, os periódicos em inglês são favorecidos na $W o S$, em detrimento de outros idiomas. Isto posto, entende-se que há subrepresentação de países e idiomas.

Tendo em vista estas limitações, bem como a possibilidade de serem analisados outros fatores, como a abordagem teórica, a metodologia adotada e os principais resultados, sugere-se futuros estudos com abordagem qualitativa. Também, o levantamento em outras bases de dados como a Scopus e Google Acadêmico podem proporcionar novas perspectivas. Propõe-se, ainda, que o foco para novas pesquisas esteja nas produções dos últimos cinco anos, diante de sua representatividade quanto ao crescimento no número de artigos publicados e indexados nas áreas de RT e GP.

\section{REFERÊNCIAS}

ARAÚJO, R. F.; ALVARENGA, L. A Bibliometria na Pesquisa Científica da Pós-Graduação Brasileira de 1987 a 2007. Encontros Bibli: Revista Eletrônica de Bibliometria e Ciência da Informação, v. 16, n. 31, p. 51-70, 2011. <https://doi.org/10.5007/15182924.2011v16n31p51>

ARCHAMBAULT, É.; CAMPBEL, D.; GINGRAS, Y.; LARIVIÉRE, V. Comparing Bibliometric Statistics Obtained From the Web of Science and Scopus. Journal of the American Society for Information Science and Technology, v. 60, n. 7, p. 1320-1326, 2009. <https://doi.org/10.1002/asi.21062>

ARMOND, L. P.; CÔRTES, F. G.; SANTOS, F. A. M.; DEMO, G.; MENESES P. P. Gestão estratégica de pessoas: revisão da produção nacional de 2006 a 2015 e agenda de pesquisa para o contexto brasileiro. In: Encontro da Associação Nacional de Pesquisa e Pós-Graduação em Administração. Anais... Costa do Sauipe, BA, Brasil, 2016.

BARBOSA, A. C. Q. Relações de trabalho e recursos humanos em busca de identidade. RAE

- Revista de Administração de Empresas, v. 45, n. Especial, p. 121-126, 2005. <http://dx.doi.org/10.1590/S0034-75902005000500010>

BARRETO, L. M. T. S.; SILVA, M. P.; FISCHER, A. L.; ALBUQUERQUE, L. G.; AMORIM, W. A. C. Temas Emergentes em Gestão de Pessoas: Uma análise da produção acadêmica. Revista de Administração da UFSM, v. 4, n. 1, p. 215-232, 2011. <http://dx.doi.org/10.5902/198346592401> 
BASU, A. Does a country's scientific 'productivity' depend critically on the number of country journals indexed? Scientometrics, v. 82, n. 3, p. 507-516, 2010. <https://doi.org/10.1007/s11192-010-0186-8>

BELCHIOR, C. A. A terceirização precariza as relações de trabalho? O impacto sobre acidentes e doenças. Revista Brasileira de Economia, v. 72, n. 1, p. 41-60, 2018. $<$ http://dx.doi.org/10.5935/0034-7140.20180003>

BOON, C.; ECKARDT, R.; LEPAK, D.; BOSELIE, P. Integrating strategic human capital and strategic human resource management. The Internacional Jounal of Human Resource Management, v. 29, n. 1, p. 34-67, 2017. <https://doi.org/10.1080/09585192.2017.1380063>

BOXALL, P. The future of employment relations from the perspective of human resource management. Journal of Industrial Relations, n. 56, v. 4, p. 578-593, 2014. <https://doi.org/10.1177/0022185614527980>

BRASIL. Lei $\mathrm{N}^{\circ}$ 13.429, de 31 de março de 2017.Altera dispositivos da Lei no 6.019 , de 3 de janeiro de 1974, que dispõe sobre o trabalho temporário nas empresas urbanas e dá outras providências; e dispõe sobre as relações de trabalho na empresa de prestação de serviços a terceiros, 2017.

CALDAS, M.; TONELLI, M. J.; LACOMBE, B. Espelho, espelho meu: meta-estudo da produção científica em Recursos Humanos nos ENANPADs da década de 90. In: Encontro Nacional Associação Nacional Dos Programas De Pós-Graduação Em Administração. Anais... Salvador, BA, Brasil, 2002.

CARVALHO NETO, A. Relações de Trabalho e Gestão de Pessoas: Entre o macro e o micro? Provocações epistemológicas. REGE - Revista de Gestão, v. 19, n. 2, p. 297-306, 2012. <https://doi.org/10.5700/rege464>

CARVALHO NETO, A.; SANT'ANNA, A. S. Relações de Trabalho e Gestão de Pessoas, dois lados de uma mesma moeda: vinculações sob a ótica do fenômeno da liderança. Revista Gestão \& Tecnologia, v. 13, n. 2, p. 2-20, 2013. <https://doi.org/10.20397/21776652/2013.v13i2.531>

CASSUNDÉ, F. R.; BARBOSA, M. A.C.; MENDONÇA, J. R. C. Terceirização e Precarização do Trabalho: Levantamento Bibliométrico sobre os Caminhos Críticos da Produção Acadêmica em Administração. TPA - Teoria e Prática em Administração, v. 6, n. 1, p. 172-194, 2016. <https://doi.org/10.21714/tpa.v6i1.28019> 
COSTA, B. S.; COSTA, S. DE S.; CINTRA, C. L. D. Os possíveis impactos da reforma da legislação trabalhista na saúde do trabalhador. Revista Brasileira de Medicina do Trabalho, v. 16, n. 1, p. 109-117, 2018. <http://dx.doi.org/10.5327/Z1679443520180097>

CHUEKE, G. V.; AMATUCCI, M. O que é bibliometria? Uma introdução ao Fórum. Revista $\begin{array}{lllllllll}\text { Eletrônica de Negócios Internacionais, } & \text { v. } & 10, & \text { n. } & 2, & \text { p. } & 1-5, & 2015 .\end{array}$ <http://dx.doi.org/10.18568/1980-4865.1021-5>

DELBRIDGE, R.; HAUPTMEIER, M.; SENGUPTA, S. Beyond the enterprise: broadening the horizons of International HRM. Human Relations, v. 64, n. 4, p. 483-505, 2011. <https://doi.org/10.1177/0018726710396388>

DEMO, G.; FOGAÇA, N.; FERNANDES, T.; SÁ, P. Políticas e práticas de gestão de pessoas: revisão bibliométrica da produção nacional em periódicos de primeira linha e institucionalização da pesquisa no Brasil entre 2010 e 2014. In: Encontro de Gestão de Pessoas e Relações de Trabalho. Anais... Salvador, BA, Brasil, 2015.

DEMO, G.; NUNES, I.; MENDES, N.; FERREIRA, L.; MELO, B. Políticas de gestão de pessoas: cenário dos estudos publicados nos periódicos da área de Administração. Organizações em contexto, v. 7, n. 14, p. 57-84, 2011. <http://dx.doi.org/10.15603/19828756/roc.v7n14p57-84>

DEMO, G.; FOGAÇA, N.; COSTA, A. C. Políticas e práticas de gestão de pessoas nas organizações: cenário da produção nacional de primeira linha e agenda de pesquisa. Cadernos EBAPE, v. 16, n. 2, p. 259-263, 2018. <http://dx.doi.org/10.1590/1679-395159073>

FERRAZ, D. L. S.; OLTRAMARI, A. P.; PONCHIROLLI, O. Gestão de pessoas e relações de trabalho. São Paulo: Atlas, 2011.

FISCHER, R. M. Pondo os pingos nos is, sobre relações do trabalho e políticas de administração de recursos humanos. In: FLEURY, M. T.; FISCHER, R. M. Processos relações do trabalho no Brasil. São Paulo: Atlas, 1987.

FREITAS, W. R. DE S.; SOUZA, M. T. S.; TEIXEIRA, A. A.; JABBOUR, C. J. C. Produção científica sobre gestão de recursos humanos e sustentabilidade: síntese e agenda de pesquisa. Revista de Ciências da Administração, v. 15, n. 36, p. 11-27, 2013. <http://dx.doi.org/10.5007/2175-8077.2013v15n36p11>

GALlON, S.; BITENCOURT, B. M.; CAMILliS, P. K.; SCHEFFER, A. B. B. Gestão de pessoas: o que andam falando por aí? Uma metanálise sobre os estudos de gestão de pessoas na área de produção. Sociais e Humanas, v. 26, n. 3, p. 588-607, 2013. 
GALLON, S.; FRAGA, A. M.; ANTUNES, E. D. D. Estudo de caso luso-brasileiro sobre políticas e práticas de expatriação. Contextus-Revista Contemporânea de Economia e Gestão, v. 17, n. 1, p. 37-64, 2019.

HELFEN, M.; SCHÜßLER, E.; SYDOW, J. How can employment relations in global value networks be managed towards social responsibility? Human Relations, v. 71, n. 12, p. 1640$1665,2018$.

KAUFMAN, B. E. The role of economics and industrial relations in the development of the field of personnel/human resource management. Management Decision, v. 40, n. 10, p. 62979, 2002.

KAUFMAN, B. E. The theoretical foundation of industrial relations and its implications for labor economics and human resource management. Industrial and Labor Relations Review, v. 64, n. 1, p. 74-108, 2010. <https://doi.org/10.1177/001979391006400104>

LACOMBE, B. M. B.; TONELLI, M. J. O discurso e a prática: o que nos dizem os especialistas e o que nos mostram as práticas das empresas sobre os modelos de gestão de recursos humanos. RAC - Revista de Administração Contemporânea, v. 5, n. 2, p. 157-174, 2011. <http://dx.doi.org/10.1590/S1415-65552001000200008>

LEGGE, K. Human Resource Management: Rhetorics and Realities. New York: Anniversary Edition, Palgrave Macmillan, 2005.

MACÊDO, D.; OLIVEIRA, R. S.; ATAIDE, J. A. R.; GOMES, C. M. F.; SANTOS, J. M.; COSTA, A. C. S. Gestão de Pessoas e Relações de Trabalho: análise da produção científica publicada nos anais do ENGPR. Revista Brasileira de Administração Científica, v. 7, n. 3, p. 66-80, 2016. <http://dx.doi.org/10.6008/SPC2179-684X.2016.003.0005>

MARRAS, J. P. Administração de recursos humanos: do operacional ao estratégico. São Paulo: Saraiva, 2016.

MASCARENHAS, A. O.; BARBOSA, A. C. Q. Produção Científica Brasileira em Gestão de Pessoas no período 2000-2010. RAE - Revista de Administração de Empresas, São Paulo, v. 53, n. 1, p. 35-45, 2013. <http://dx.doi.org/10.1590/S0034-75902013000100004>

MENEGHINI, R. The benefits of and challenges for publishing scientific journals in and by emerging countries. EMBO Reports, v. 13, n. 2, p. 106-108, 2012. <http://dx.doi.org/ 10.1038/embor.2011.252> 
MENESES, P. P. M.; COLEHO JÚNIOR, F. A.; FERREIRA, R. R.; PASCHOAL, T.; SILVA FILHO, A. I. A produção científica brasileira sobre a gestão de recursos humanos entre 2001 e 2010. RAM - Revista de Administração Mackenzie, v. 15, n. 4, p. 110-134, 2014. <http://dx.doi.org/10.1590/1678-69712014/administracao.v15n4p110-134>

MONGEON, P.; PAUL-HUS, A. The journal coverage of Web of Science and Scopus: a comparative analysis. Scientometrics, v. 106, n. 1, p. 213-228, 2016.

NAPOLEÃO, R.; CARVALHO NETO, A. M.; LIMA, G. S.; GONÇALVES, P.; ALMEIDA, T. Responsabilidade Social Empresarial e Gestão de Pessoas: a perspectiva dos trabalhadores de uma empresa pública. Contextus-Revista Contemporânea de Economia e Gestão, v. 12, n. 2, 2014.

OLTRAMARI, A. Carreira: panorama de artigos sobre o tema. In: Encontro Nacional Associação Nacional Dos Programas De Pós-Graduação Em Administração. Anais... Rio de Janeiro, RJ, Brasil, 2008.

OLIVEIRA, A. A. D.; LIMA, C. S. L.; MORAIS, K. K. C. Bibliometria e metassíntese de estudos sobre trabalhos publicados na revista Psicologia \& Sociedade. Psicologia \& Sociedade, v. 28, n. 3, p. 572-581, 2016. <http://dx.doi.org/10.1590/1807-03102016v28n3p572>

PASSOS, R. F.; VIDA, W. C. L. Tendência de Publicação e Impacto de Artigos em Inglês em Revistas Brasileiras, Alemãs, Espanholas e Francesas. In: Workshop de Editoração Científica. Anais... Campos do Jordão, SP, Brasil, 2014.

PARENTE, T. C.; FISCHER, A. L. A Relação entre Recursos Humanos e Sustentabilidade como tema emergente: Uma análise bibliométrica. Revista Alcance, v. 21, n. 3, p. 398-421, 2014. <http://dx.doi.org/10.14210/alcance.v21n3.p398-421>

PACKER, A. Os periódicos brasileiros e a comunicação da pesquisa nacional. Revista USP, v. 89, n. Especial, p. 26-61, 2011. 〈https://doi.org/10.11606/issn.2316-9036.v0i89p26-61>

PATTON, W. D. Teaching Labor Relations. Review of Public Personnel Administration, v. 14, n. 4, p. 52-64, 1994. <https://doi.org/10.1177/1052562910383967>

PAAUWE, J.; BOON, C. Strategic HRM: A critical review. In: D. COLLINGS; G. WOOD; L. SZAMOSI (Eds.), Human Resource Management: A critical introduction. Routledge, 2018. 
RODRIGUES, R. S.; QUARTIERO, E.; NEUBERF, P. Periódicos Científicos Brasileiros Indexados Na Web Of Science E Scopus: estrutura editorial e elementos básicos. Informação e Sociedade: Estudos, v. 25, n. 2, p. 117-138, 2015.

ROGERS, M. Problems of human relations in industry. Sociometry, v. 9, n. 4, p. 350-371, 1946. <https://doi.org/10.2307/2785500>

SARSUR, A. M.; CRUZ, M. V. G.; AMORIM, W. A. C.; FISCHER, A. R.; KASSEM, M. R. Gestão de Recursos Humanos e Relações de Trabalho no Brasil: a emergência da crise. Proceedings of the II International Meeting of ISSOW, p. 314-330, 2017.

SILVA, N. B., ORSI; A.; NAKATA, L. E. Análise da Produção Acadêmica sobre Gestão Internacional de Recursos Humanos entre 2001 e 2011. ReCaPe - Revista de Carreiras e Pessoas, v. 3, n. 3, p. 50-60, 2013. <https://doi.org/10.20503/recape.v3i3.17703>

TONELLI, M. J.; CALDAS, M. P.; LACOMBE, B. M. B.; TINOCO, T. Produção acadêmica em recursos humanos no Brasil: 1991-2000. RAE - Revista de Administração de Empresas, v. 43, n. 1, p. 1-18, 2003. <http://dx.doi.org/10.1590/S0034-75902003000100011>

TONELLI, M. J.; WILNER, A. Tendências na área de gestão de pessoas. GV-Executivo, v. 17, n. 4, p. 3, 2018.

TORRES, C. C.; FERREIRA, M. C.; FERREIRA, R. R. Trabalhadores descartáveis? Condição de terceirização e mal-estar no trabalho. Estudos e Pesquisas em Psicologia, v. 16, n. 3, p. 725-735, 2016. <https://doi.org/10.12957/epp.2016.31446>

URBIZAGASTEGUI, R. A.; RESTREPO-ARANGO, C. Crescimento da literatura sobre bibliometria, informetria e cientometria no Brasil. Pesquisa Brasileira em Ciência da $\begin{array}{lllllllll}\text { Informação } & \text { e Biblioteconomia, } & \text { v. } & 12, & \text { n. } & 2, & \text { p. } & 2-31,\end{array}$ <https://doi.org/10.22478/ufpb.1981-0695.2017v12n2.36834>

VENÂNCIO, D. M.; MARTINS, C.; DUTRA, A.; STEINBACH, A. Análise da produção científica sobre gestão de pessoas nos anais do Encontro Nacional da Associação de PósGraduação Em Administração-(Enanpad) de 2001 a 2010. Revista de Administração, v. 12, n. 2, p. 159-181, 2014.

WOOD JR, T.; TONELLI, M. J.; COOKE, B. Colonização e neocolonização da gestão de recursos humanos no Brasil (1950-2010). RAE - Revista de Administração de Empresas, v. 51, n. 3, p. 232-243, 2011. <http://dx.doi.org/10.1590/S0034-75902011000300004> 
WRIGHT, P. M.; DUNFORD, B. B.; SNELL, S. A. Human resources and the resource based view of the firm. Journal of Management, v. 27, n. 6, p. 701-721, 2001. <https://doi.org/10.1177/014920630102700607>

ZHU, D.; CUNNINGHAM, S.; PORTER, A. L.; CARLISIE, J. A process for mining science $\&$ technology documents databases, illustrated for the case of "knowledge discovery and data mining". Ciência da Informação, v. 28, n. 1, 1999. <http://dx.doi.org/10.1590/S010019651999000100002> 